\title{
LABORATORY INVESTIGATION ON THE EFFECTIVENESS OF AN OVERSPILL BASIN IN REDUCING WAVE OVERTOPPING ON MARINA BREAKWATERS
}

\author{
Lorenzo Cappietti ${ }^{1}$ and Pier Luigi Aminti ${ }^{1}$
}

\begin{abstract}
This paper presents laboratory experiments on scale models of marina breakwaters conducted to assess the effectiveness of an overspill basin in reducing wave overtopping. Six different breakwater models were tested under eight different wave conditions. The comparisons between the overtopping measurements on a classical shaped breakwater model and those conducted on models characterized by the inclusion of overspill basins have proved the effectiveness of this new design. Moreover, increasing the height of the wave wall up to the value that induces the same reduction of the overtopping obtained by the inclusion of overspill basins is also reviewed. Some analysis on mean overtopping discharges as well as analysis on maximum overtopping volumes are reported.
\end{abstract}

Keywords: overtopping; harbor breakwaters; physical model;

\section{INTRODUCTION AND MOTIVATIONS}

The control of wave overtopping on harbor breakwaters is of crucial importance to ensure harbor tranquility, safety and to avoid the damage of infrastructures and boats. According to the authors' knowledge, a considerable number of existing Italian marina breakwaters suffer all too frequently and too intensively from wave overtopping events (e.g. Fig. 1) and it is likely that such problems plague many other marinas around the world.

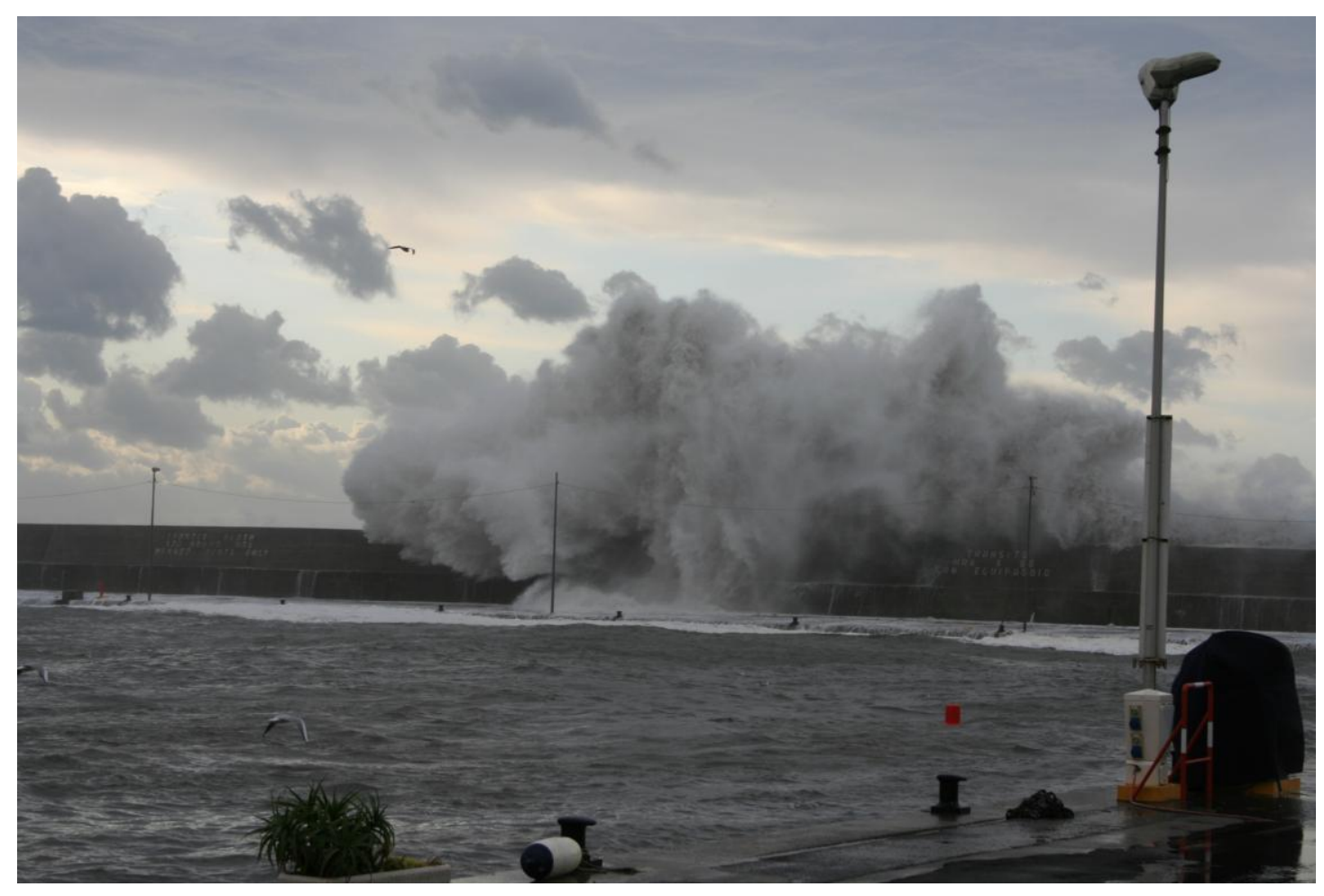

Figure 1. Classical examples of overtopping. Marina of Chiavari (Genova, Italia) October 30th 2008. During the last 10 years, this marina has been affected too frequently and too intensively by overtopping events. At present, re-designing works are being carried out to convert the existing, classical shaped breakwater section into a section equipped with an overspill basin.

During the last 10 years, significant damages to structures and boats have been all too frequent, economically unsustainable and therefore no longer tolerable. The reasons for this apparent increment in the frequency of damages are not discussed in this paper (e.g. climate change, lack of design wave

1 Department of Civil and Environmental Engineering, University of Florence, Via S. Marta 3, Florence, 50139, Italy 
data, ... etc.) while it is, rather, focused on technical solutions for improving the efficiency of existing marina breakwaters in order to reduce the frequency and the intensity of overtopping events to tolerable values. It could become a strategic need if the predicted increment in the sea level is confirmed in the next years.

It is well known that overtopping reduction can be achieved, e.g., by a suitably designed wave wall, though this may lead to an undesirably high level of its crest in terms of adverse social and environmental disturbance. Other alternatives can be employed such as a recurred wave wall (see for instance Pearson et al. 2004) and one major step forward has been the production of the updated general design guidance in EurOtop (2008). At the state of the art, the use of an overspill basin on top of marina breakwaters (Fig. 2) has received less attention despite being a promising alternative, as proved by Aminti and Franco (2001), Burcharth et al, (2006), Geeraerts et al. (2006), Crema et al. (2009) and, in case of dikes, as proved by the group of the project ComCoast (2007).

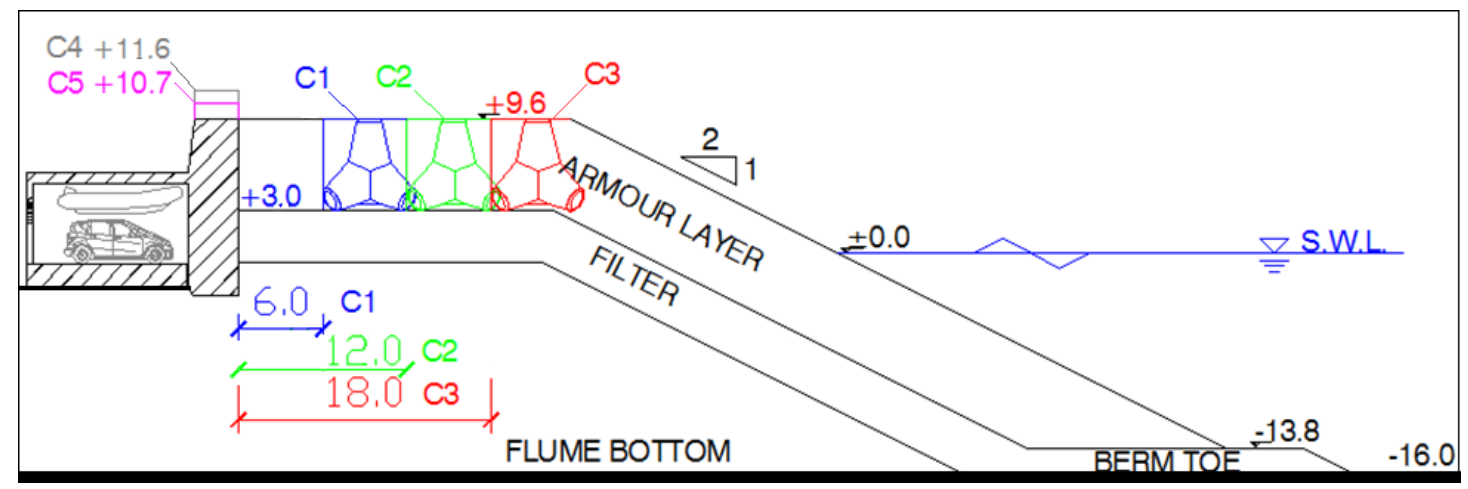

Figure 2. Schematic layout of the tested breakwater models characterized by overspill basins of different volumes. Units are $\mathrm{cm}$ and the measurements are related to the scaled model.

Often, the existing Italian rubble-mound marina breakwaters affected by this problem are characterized by a fairly low wave wall and a wide emerged berm so that the building of an overspill basin is a practical and economically viable option. However, knowledge of its effectiveness in reducing wave overtopping still needs to be increased in order to develop guidance in the design phase. Moreover, if the building of the overspill basin is achieved by means of the removal of the armour layer elements located in front of the wave wall, it may be exposed to an increment of the wave impact loads that may lead to a possible failure. At present, there is no knowledge concerning these specific wave loads.

\section{OBJECTIVES AND METHODOLOGY}

The objective of this work is to contribute to the present knowledge of the effectiveness of an overspill basin to reduce wave overtopping on marina breakwaters. The methodological framework of the study was scale-model laboratory experiments. This paper presents a new data set of measurements of overtopping on harbor breakwaters and wave loads acting on the wave wall in the presence of overspill basins characterized by different design parameters. Preliminary results analyses concerning the efficiency of the overspill basin in the attenuation of the mean overtopping discharges and maximum overtopping volumes are presented.

\section{LABORATORY EXPERIMENTS}

The experiments were conducted in the wave-current flume of the Maritime Construction Laboratory of the Civil and Environmental Engineering Department of Florence University (www.unifi.it/labima). The wave-current flume is $50.0 \mathrm{~m}$ long $0.8 \mathrm{~m}$ wide and $0.8 \mathrm{~m}$ high, it is equipped with a piston type wave maker and with a bi-directional recirculation system.

\section{Tested models}

Six different scale-model breakwater sections were tested on a fixed bottom. The models are representative of a classical multilayer rubble-mound breakwater scaled 1:50. In the following parts of the present paper the measurements are given for the prototype scale when not otherwise specified. 
For all the tested models, the following design parameters were maintained constant: i) the water depth at the breakwater toe was $8.0 \mathrm{~m}$; ii) the breakwater was characterized by an armour layer made from natural rock elements of a weight between $7.0 \mathrm{t}$ and $12.5 \mathrm{t}$, and a filter layer made from natural rock elements of a weight between $1.8 \mathrm{t}$ and $3.1 \mathrm{t}$; iii) the core elements used to build the models were selected in order to minimize the scale effects arising from the worst reproduction of the rubble-mound permeability if the 1:50 geometrical scale was used (the Burchart et al., 1999, methodology was applied so the corrected core scale reduction resulted 1:36; iv) the seaward rubble-mound slope was $1: 2$.

The reference configuration, hereafter referred to as the classical shaped breakwater $\mathrm{C} 0$, has the wave wall crest at the same level as the armour layer berm crest, i.e. $+4.8 \mathrm{~m}$. The configurations $\mathrm{C} 1, \mathrm{C} 2$ and $\mathrm{C} 3$ where obtained from the $\mathrm{C} 0$ by removing part of the armour layer in front of the wave wall in order to build the overspill basins of volumes $9 \mathrm{~m}^{3} / \mathrm{m}, 18 \mathrm{~m}^{3} / \mathrm{m}$ and $27 \mathrm{~m}^{3} / \mathrm{m}$. The level of the bottom of the basins was $+1.5 \mathrm{~m}$ above the SWL, its depth was $3.3 \mathrm{~m}$, the two lateral boundaries were, the first, the wave wall itself and the second, a row of double layer tetrapods of $20 \mathrm{t}$. The tetrapods were used to assure the stability of the armour on the seaward boundary of the basin. In this position, the waveinduced water flow falling into the basin leads to extra loads that induce instability in the preexisting natural rock elements. The models $\mathrm{C} 4$ and $\mathrm{C} 5$ were obtained from the classical shaped breakwater $\mathrm{C} 0$, increasing the height of the wave wall crest level by $1.0 \mathrm{~m}$ and $0.5 \mathrm{~m}$ thus reaching $5.8 \mathrm{~m}$ and $5.3 \mathrm{~m}$ above the mean sea level. While the configuration $\mathrm{C} 0$ was tested in order to become the reference configuration for understanding the effectiveness of building an overspill basin (configurations C2, C3 and $\mathrm{C} 4$ ), the configurations C4 and C5 were tested in order to highlight the value of the increase in height of the wave wall that induces the reduction of the overtopping as much as the reduction obtained by the inclusion of an overspill basin.

\section{Flume setting, model instrumentation, test methodology}

The flume water depth in front of the wave maker was $55.5 \mathrm{~cm}$, the bottom was horizontal up to $20.5 \mathrm{~m}$ away from the wave maker, where the reach of the bottom of the slope of 1/12.4 was settled for $1.2 \mathrm{~m}$, then a second reach of the bottom of the slope of $1 / 28.5$ was built for $6.0 \mathrm{~m}$ and finally a third reach of the bottom of the slope of $1 / 55$ was placed for the last $4.9 \mathrm{~m}$, i.e. up to the breakwater toe, where the water depth was $16.0 \mathrm{~cm}$ ( $8.0 \mathrm{~m}$ prototype scale).

Resistive level gauges, of an accuracy of $0.1 \mathrm{~mm}$ (scale model), were used to measure the effective wave generation. One wave gauge was positioned at a distance of $7.0 \mathrm{~m}$ away from the wave maker where the water depth was $55.5 \mathrm{~cm}$, while an array of 4 wave gauges, spaced at about $25-30 \mathrm{~cm}$, was positioned at a distance of about $28.0 \mathrm{~m}$ away from the wave maker (about $4.0 \mathrm{~m}$ far from the breakwater toe) in water depth of about $23.0 \mathrm{~cm}$ (11.5 m prototype scale).

Four pressure transducers, Keller $46 \mathrm{X}$ of an accuracy of $0.2 \mathrm{mbar}$ (scale model), were used to measure the wave-induced pressure on the wave wall. The pressure transducers were positioned as depicted in Fig. 3.
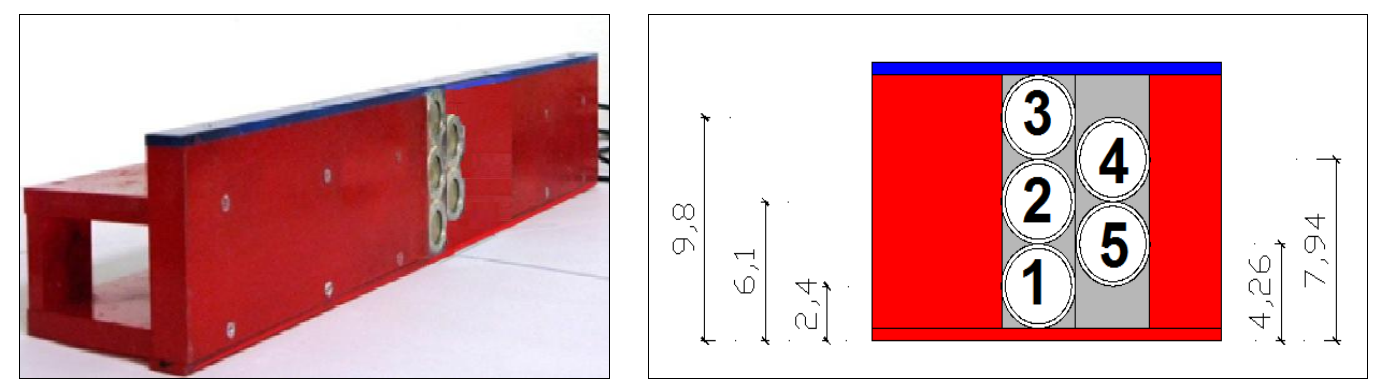

Figure 3. The tested wave wall equipped with pressure transducers for the measurement of wave-induced pressure. Units are $\mathrm{cm}$ at the model scale.

Four load cells, CTCA1K5 of an accuracy of $1.0 \mathrm{~g}$ each (scale model), were used to measure the wave-by-wave overtopping volumes and the mean overtopping discharges. A suspended tank was connected to the four load cells and the overtopping volumes were captured at the wave wall by means of a chute. This system ensures an accuracy of $4.0 \mathrm{~g}$ (scale model) in the measurements of the overtopping volumes. 
Eight wave conditions were tested, W1, W2, W3,..,W8 and each wave attack was 3600 minutes long (scale model), i.e. from 2000 to 3000 peak-periods. The duration of the wave attacks W1,W2, W3, W4, W5 and W6 was partitioned into 3 sub-intervals, 20 minutes long, and the overtopping volumes were captured by a $30 \mathrm{~cm}$ wide chute (scale model). The duration of the remaining wave attacks, i.e. W7 and W8, was partitioned into 6 sub-intervals, 10 minutes long, and the chute was $20 \mathrm{~cm}$ wide (scale model).

\section{Effective Wave conditions}

Waves were generated in a water depth of $55.0 \mathrm{~cm}$ and were characterized by a JONSWAP spectrum. The effective incident wave conditions were obtained by reflection analysis of wave measurements collected at the wave gauge array positioned in front of the breakwater. The method of Goda and Suzuki (1976) was used to perform the reflection analysis. The wave parameters, as well as the common dimensionless parameters, are reported in Table 1.

It is worth noting that the experimental ranges in terms of the breaker index $\left(0.043<\mathrm{H}_{\mathrm{moi}} / \mathrm{d}<\right.$ $0.053)$ and in terms of the wave steepness $\left(0.02<\mathrm{H}_{\mathrm{m} 0 \mathrm{i}} / \mathrm{L}_{0}<0.03\right)$ prove that the incident wave conditions were of the kind of broken waves on a gentle foreshore (1/55). Anyway the incident spectrum still shows a clear main peak but a secondary lower peak appeared at higher frequencies. The maximum incident measured waves $(0.04 \%)$ were 1.64 times the significant wave heights instead of the expected value, i.e. 1.95, that characterizes deep water conditions (Fig. 4).

\begin{tabular}{|c|c|c|c|c|c|c|c|c|}
\hline Wave & $\begin{array}{c}\mathrm{H}_{\mathrm{m} 0 \mathrm{i}} \\
{[\mathrm{m}]}\end{array}$ & $\begin{array}{l}\mathrm{T}_{\mathrm{m}-1,0} \\
{[\mathrm{~s}]}\end{array}$ & $Y$ & $\mathrm{H}_{\mathrm{mo}} / \mathrm{L}_{0}$ & $\mathrm{H}_{\mathrm{moi}} / \mathrm{d}$ & $\mathrm{R}_{\mathrm{c}} / \mathrm{H}_{\mathrm{m0i}}$ & $\xi_{\mathrm{m}-1,0}$ & $\mathrm{~V}_{\mathrm{b}} /\left(\mathrm{H}_{\mathrm{m} 0 \mathrm{i}} \mathrm{L}_{0}\right)$ \\
\hline W1 & 5.0 & 10.3 & 2 & 0.03 & 0.43 & $0.96-1.16$ & 2.9 & $0.011-0.033$ \\
\hline W2 & 5.2 & 10.6 & 5 & 0.03 & 0.44 & $0.92-1.11$ & 2.9 & $0.010-0.030$ \\
\hline W3 & 5.6 & 11.5 & 2 & 0.03 & 0.48 & $0.85-1.03$ & 3.0 & $0.008-0.024$ \\
\hline W4 & 5.7 & 11.9 & 5 & 0.03 & 0.48 & $0.85-1.02$ & 3.1 & $0.007-0.022$ \\
\hline W5 & 5.6 & 13.0 & 2 & 0.02 & 0.47 & $0.86-1.04$ & 3.4 & $0.006-0.018$ \\
\hline W6 & 5.6 & 13.3 & 5 & 0.02 & 0.47 & $0.86-1.04$ & 3.5 & $0.006-0.018$ \\
\hline W7 & 6.3 & 13.0 & 2 & 0.02 & 0.53 & $0.77-0.93$ & 3.2 & $0.005-0.017$ \\
\hline W8 & 6.2 & 13.6 & 5 & 0.02 & 0.53 & $0.77-0.93$ & 3.4 & $0.005-0.016$ \\
\hline
\end{tabular}

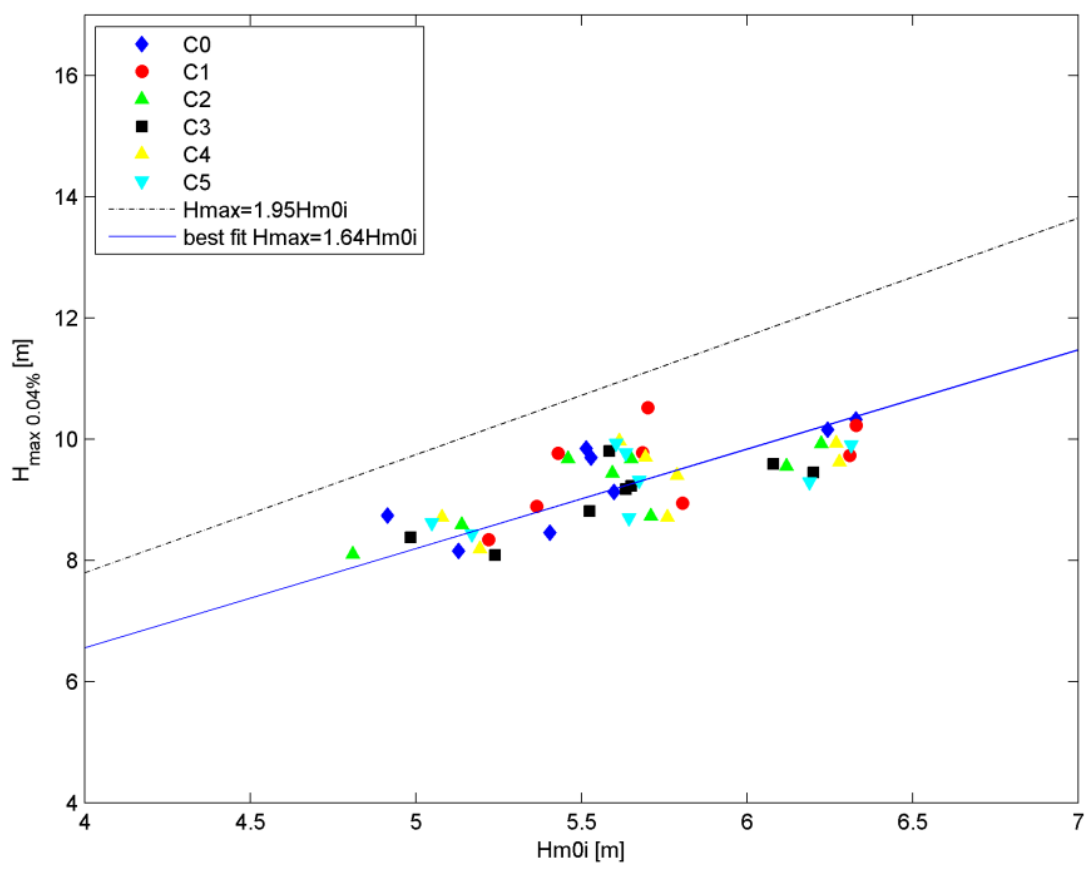

Figure 4. Significant incident wave heights versus the maximum incident wave heights $(0.04 \%)$. 
Concerning the wave-structure interaction, we observe that the range values of the breaking parameter $\left(2.9<\xi_{\mathrm{m}-1,0}<3.5\right)$ and those of the relative freeboard $\left(0.77<\mathrm{R}_{\mathrm{c}} / \mathrm{H}_{\mathrm{m} 0}<1.16\right)$ highlight that the wave breaking on the armour slope approaches the surging type and that the tested breakwaters are relatively low-crested.

\section{OVERTOPPING ANALYSIS}

This paragraph reports a preliminary analysis of the overtopping phenomenon. The analysis of the wave-induced pressure on the wave wall will be reported in a more comprehensive paper to be submitted in due course for publication.

The aim of this analysis is to highlight the following aspects: i) present measurements versus state of the art measurements; ii) the effectiveness of overspill basins ( $\mathrm{C} 1, \mathrm{C} 2$ and $\mathrm{C} 3$ ) in reducing wave overtopping in respect to a classical breakwater $(\mathrm{C} 0)$; iii) dependency of the overtopping on the volume of the overspill basin; iv) the effectiveness of the overspill basin versus the effectiveness of increasing the height of the wave wall.

The mean overtopping discharges measured in this study are plotted in Fig. 5 in terms of dimensionless discharges versus the dimensionless freeboard. In order to compare our measurements with state of the art measurements, Fig. 5 also shows the values predicted by the most common empirical-deterministic formulation (see for instance EurOtop2008) once corrected by the Besley (1999) reduction factor to take into account the wide crest present in the C0 model. It is evident that our measurements are lower than the predicted values by about a factor of 3 . Considering that the variability in state of the art overtopping measurements is quite often much higher than a factor of 3 , our measurements could be considered as valid. Also, the measurements conducted on the models equipped with overspill basins, C1, C2 and C3, are depicted in Fig. 5 and, as expected, these mean overtopping discharges are lower than those measured on the classical breakwater.

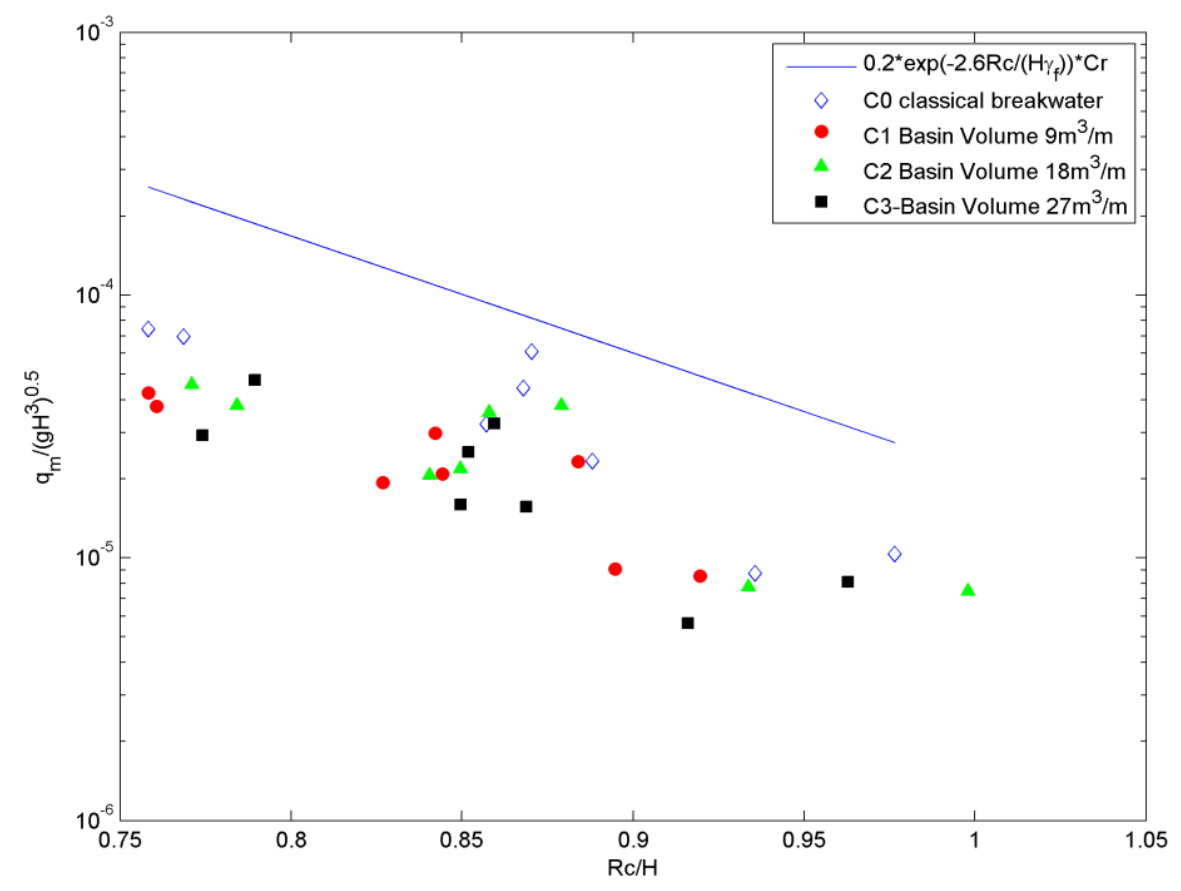

Figure 5. Dimensionless mean overtopping discharges versus dimensionless breakwater freeboard; the dots are related to the experimental measurements taken in the present study, the line shows the values predicted from the state of the art empirical-deterministic formulation. $\mathrm{Cr}$ is the reduction factor proposed by Besley (1999) for wide crest breakwaters.

The maximum overtopping volumes versus the mean overtopping discharges are reported in Fig. 6. This graph shows that a single overtopping event transports a volume of water that is more than 1000 times higher than the mean discharge.

Fig. 7 and Fig. 8 show the mean discharges and the maximum overtopping volumes measured on the breakwater models equipped with overspill basins, i.e. models $\mathrm{C} 1 \mathrm{C} 2$ and $\mathrm{C} 3$, versus the same 
quantities measured on the classical-shaped breakwater, i.e. model $\mathrm{C} 0$. These graphs prove that the effectiveness of overspill basins in reducing overtopping increases by increasing the magnitude of the phenomenon and reaches a factor of about 2.0, within the conditions tested in the present study. Once this effectiveness has been proved, it is certainly of interest to understand whether its magnitude is a function of the volume of the overspill basin.

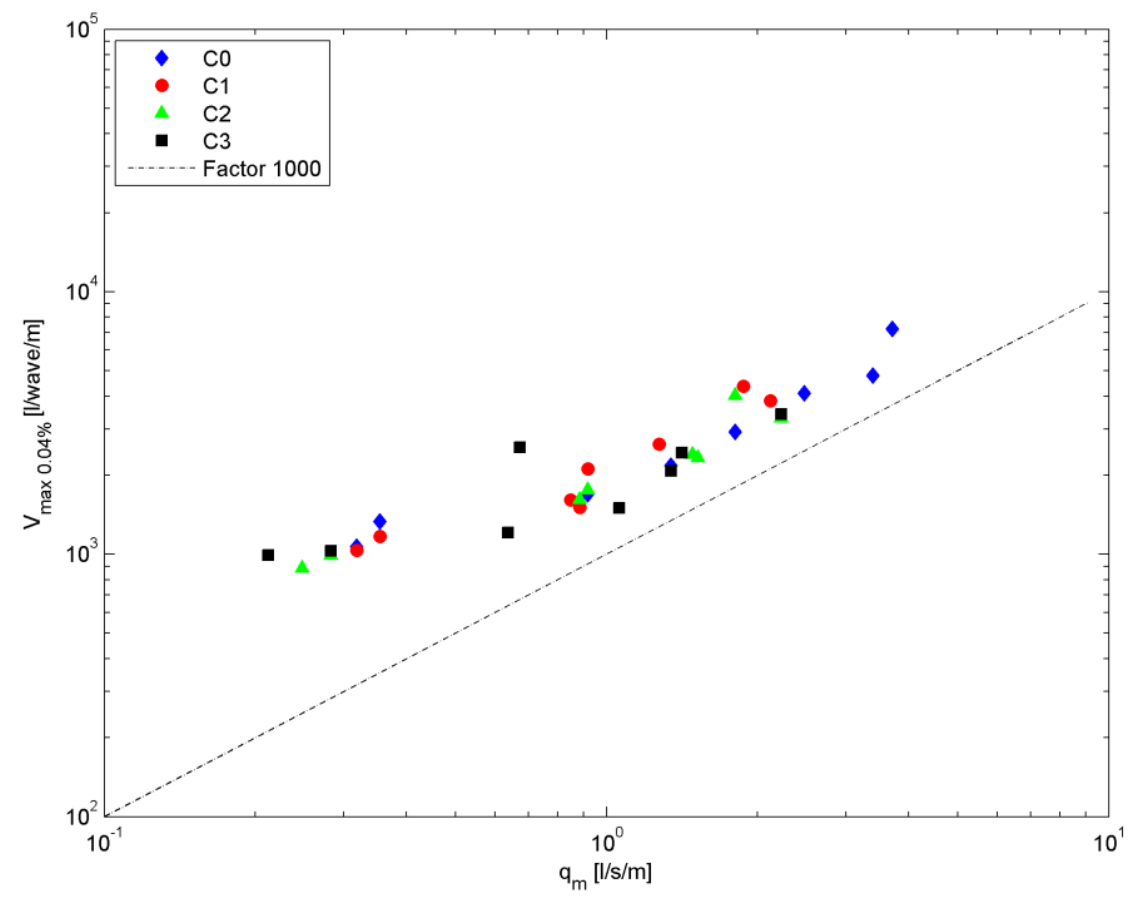

Figure 6. Maximum overtopping volumes versus mean overtopping discharges.

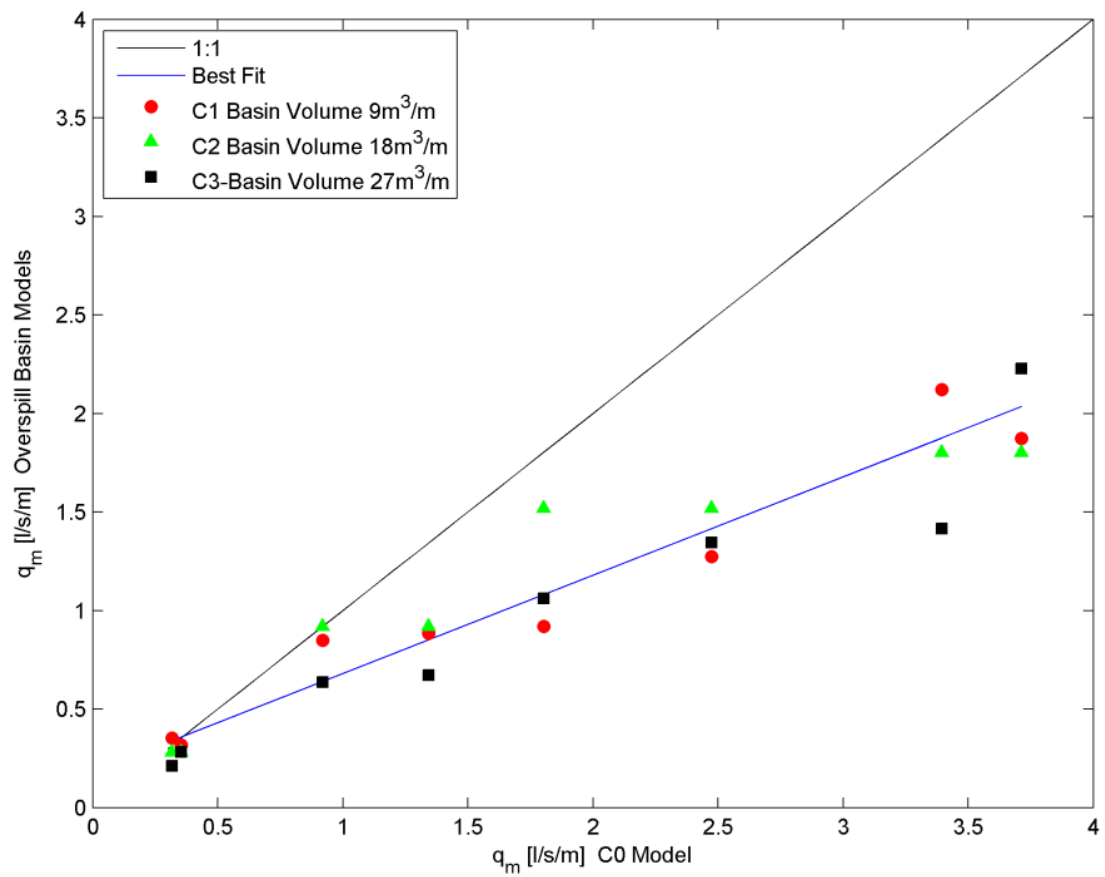

Figure 7. Mean overtopping discharges measured on models equipped with overspill basins (C1, C2 and C3), versus mean overtopping discharges measured on the classical-shaped breakwater (model $\mathrm{CO}$ ). 


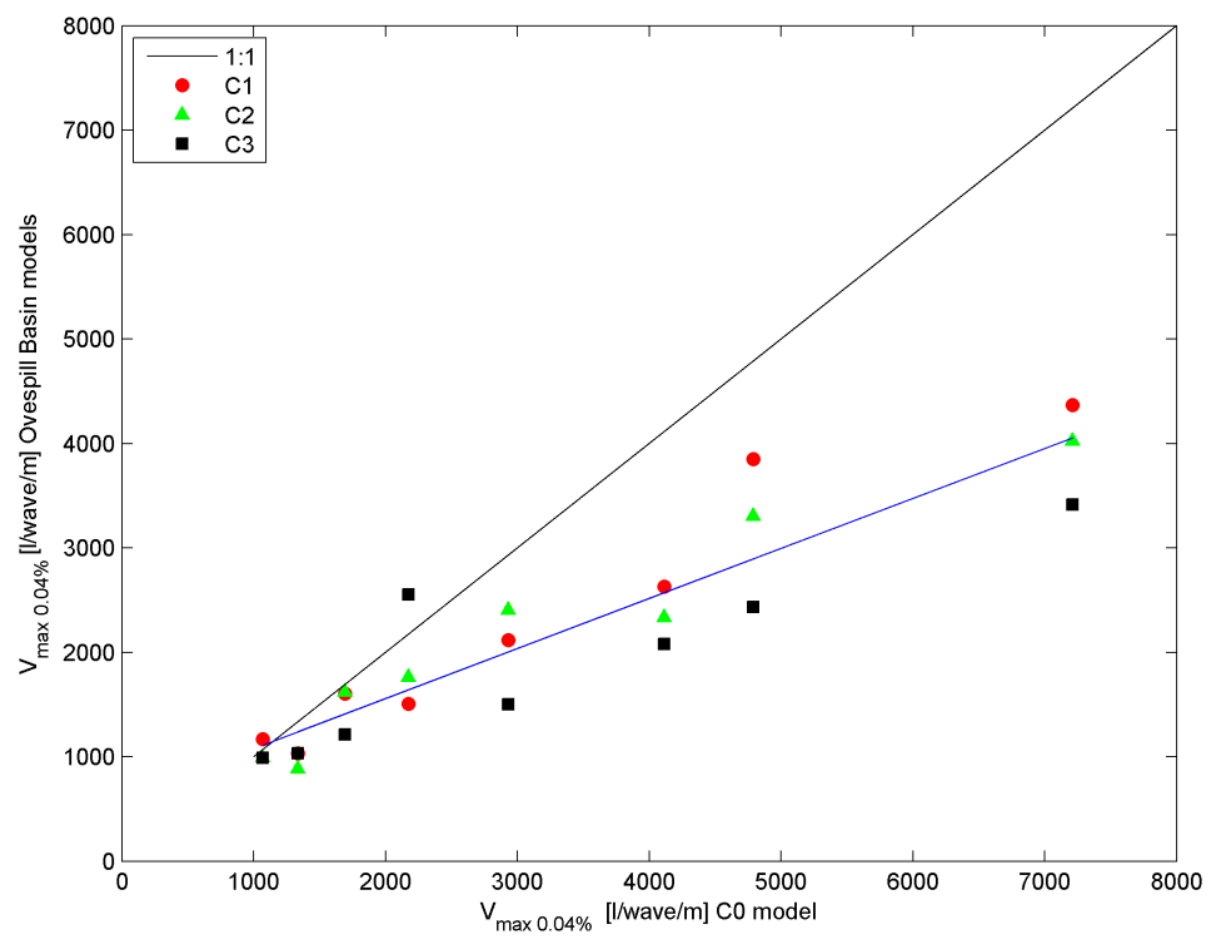

Figure 8. Maximum overtopping volumes measured on models equipped with overspill basins (C1, C2 and C3), versus Maximum overtopping volumes measured on a classical-shaped breakwater (model $\mathrm{CO}$ ).

The analysis of the dependency of the mean overtopping discharges on the volume of the overspill basin is summarized in Fig. 9 that also highlights the influence of breakwater freeboard. Within the range of the conditions tested in the present work, the relative barrier freeboard is still the main parameter in control of the overtopping and the increase of the overspill basin volume is associated with a weaker trend of reduction of the overtopping discharge.

Finally, in order to measure the effectiveness of building an overspill basin compared to the alternative of increasing the height of the wave wall, the models $\mathrm{C} 1, \mathrm{C} 2$ and $\mathrm{C} 3$ have been compared with the models $\mathrm{C} 4$ and $\mathrm{C} 5$. The mean overtopping discharges as well as the maximum overtopping volumes in presence of the overspill basins are always lower than the same quantities measured on the C5 model which has a wave wall $0.5 \mathrm{~m}$ higher. In the case of increasing the height of the wave wall up to $1.0 \mathrm{~m}$ as in the $\mathrm{C} 4$ model, the comparisons are reported in Figs. 10 and 11. Fig. 10 illustrates that the mean overtopping discharges measured in the case of building overspill basins are close to the values obtained in the case of increasing the height of the wave wall up to $1.0 \mathrm{~m}$. However, Fig. 11 shows that, in terms of limiting the maximum overtopping volumes, building an overspill basin is still more effective, up to a factor of 2 , than increasing the height of the wave wall up to $1.0 \mathrm{~m}$. 


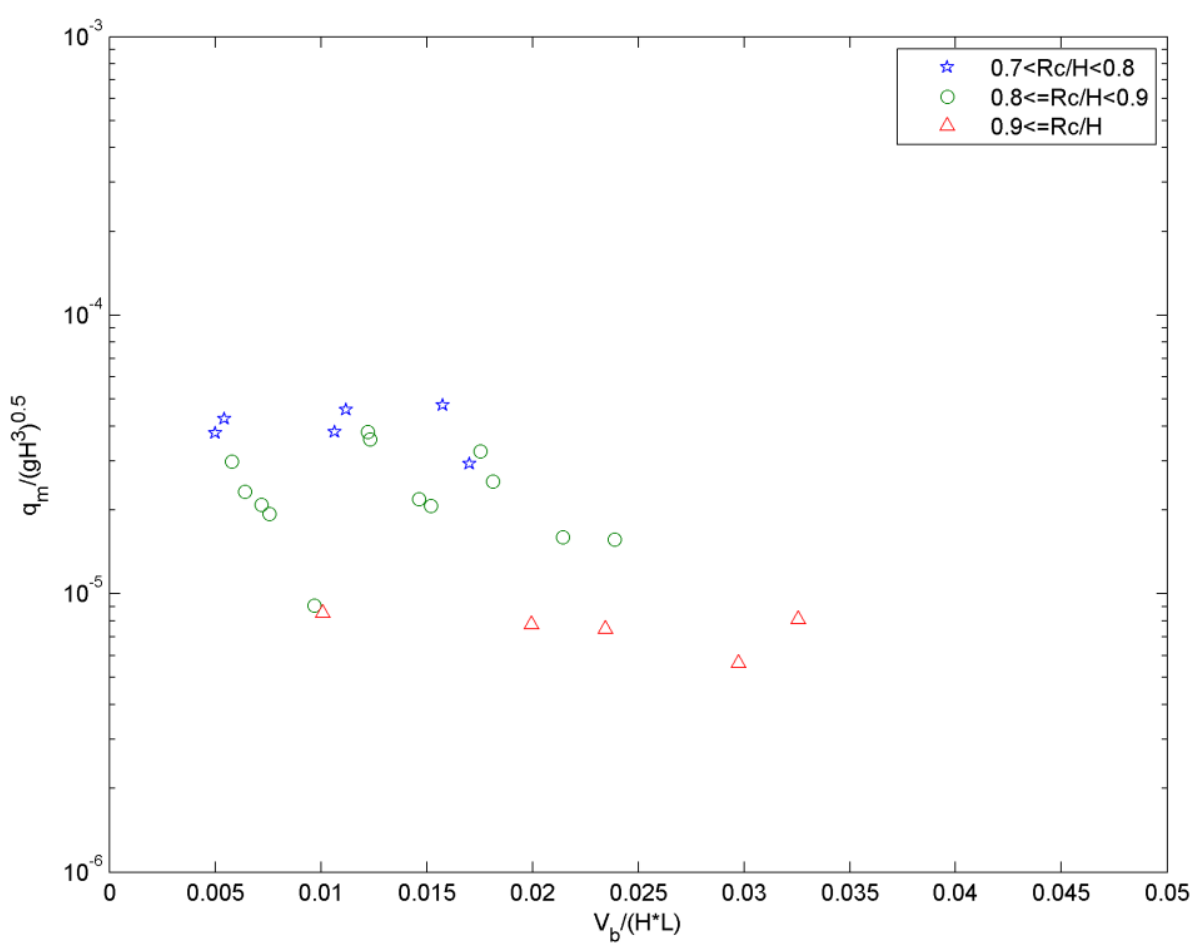

Figure 9. Dimensionless mean overtopping discharge versus dimensionless overspill basin volumes.

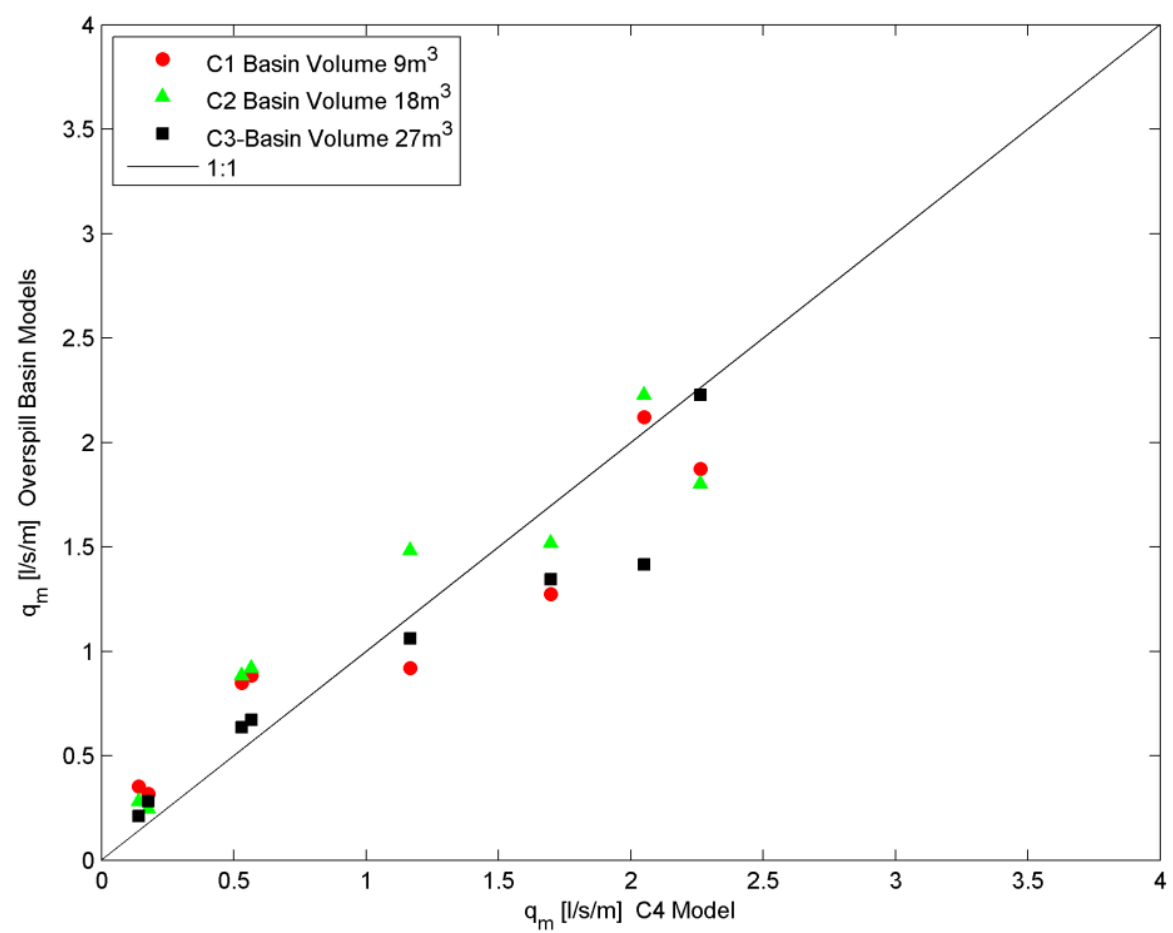

Figure 10. Mean overtopping discharges measured on models equipped with overspill basins, C1, C2 and C3, versus mean overtopping discharges measured on the model C4 characterized by a wave wall $1 \mathrm{~m}$ higher but without the overspill basin. 


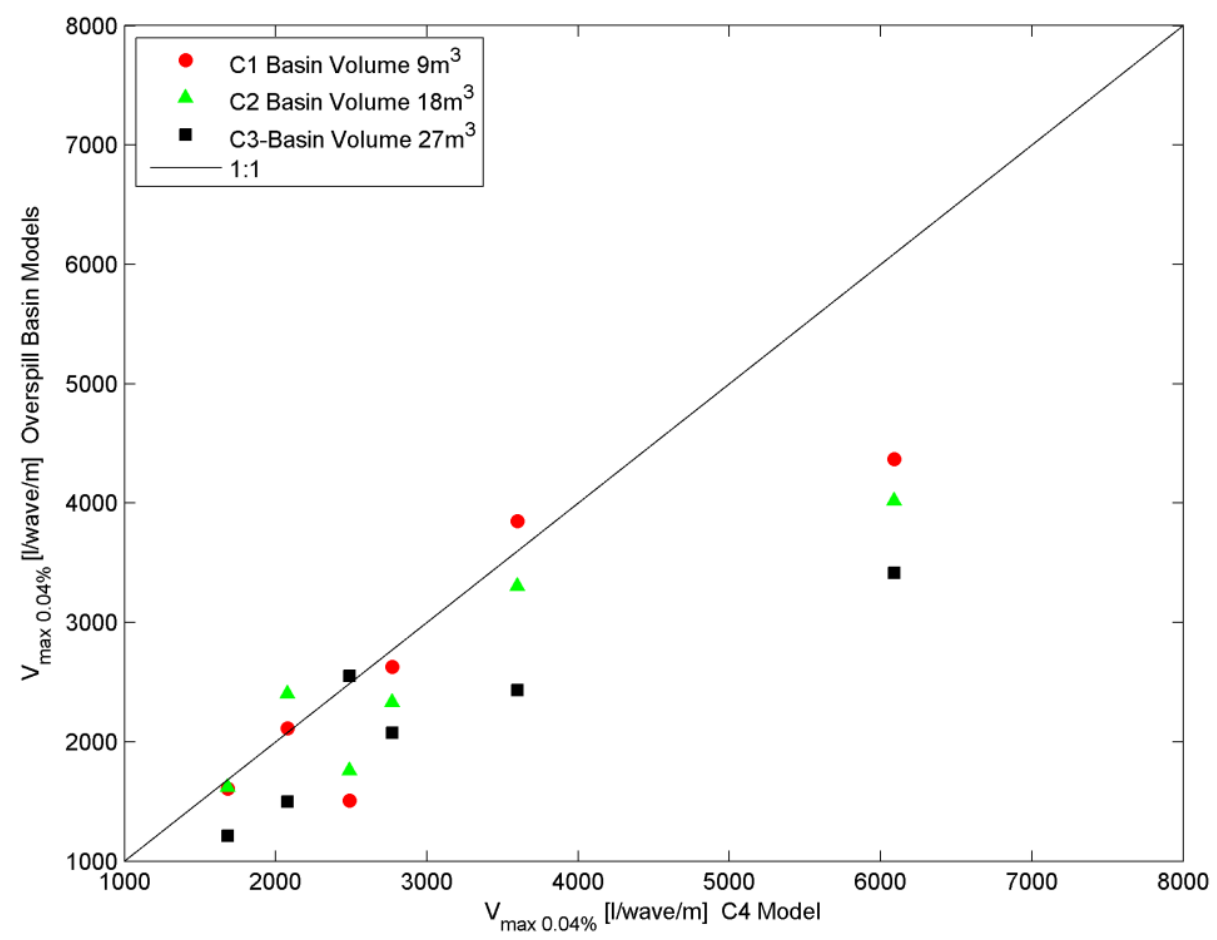

Figure 11. Maximum overtopping volumes measured on models equipped with overspill basins, C1, C2 and C3, versus Maximum overtopping volumes measured on the model $\mathrm{C} 4$ without the overspill basin but characterized by a wave wall $1 \mathrm{~m}$ higher.

\section{CONCLUSION}

Experimental measurements of wave overtopping on scale models of rubble-mound marina breakwaters were taken in order to assess the effectiveness of building an overspill basin in front of the breakwater wave wall. Comparisons between the measurements carried out on a model representing a classical-shaped breakwater section and measurements on models equipped with overspill basin proved that this latter design decreases overtopping by up to a factor of 2 , at least within the range of experimental conditions tested in the present study.

Considering as an alternative measure for reducing wave overtopping, increasing the height of the wave wall, the experimental measurements demonstrated that to reach the same reduction of mean overtopping discharges that was obtained by the inclusion of the overspill basin, it is necessary to elevate the wave wall up to $1.0 \mathrm{~m}$. Although these two alternatives are almost equivalent in terms of mean overtopping discharges, the overspill basin, however, is still more effective in reducing the wave by wave overtopping by up to a factor of 2 .

The dependence of the overtopping on the volume of the overspill basin was tested by repeating the same wave attacks on different models. The measurements highlighted that the breakwater freeboard remains the most important parameter that controls the overtopping while the volume of the overspill basin has a weaker influence.

It is worth noting that these results are related to the specific breakwater designs and wave conditions tested in the present study. However, the breakwaters' characteristics as well as the wave conditions of the present experimental campaigns were designed to be a good representation of many Italian marina breakwaters situated on the northern Tyrrhenian sea. Furthermore, these results can be of wider interest when considered in terms of dimensionless quantities as is the case in some of the preliminary analyses reported here.

Apart from the aspects related to the effectiveness of reducing wave overtopping, some other design aspects are worth mentioning as follows: i) in the case of existing breakwaters in need of being re-designed in order to limit overtopping, the building of an overspill basin could contribute to maintaining the same elevation of the wave wall or, at least, to reduce the increase in height required if should a significant reduction be needed; ii) still in the case of existing breakwaters, if the building of the overspill basin is obtained by the removal of the armour stones in front of the wave wall, it could be 
subjected to a stronger wave load that could induce instability; iii) the level of the bottom of the overspill basin should be placed at an elevation higher than the expected design sea level or else the dry volume of the basin would be reduced and hence also its effectiveness; iv) the wave action on the armour stone on the seaward boundary of the overspill basin will increase significantly; thus heavier elements could be required to assure stability (tetrapods were used for the present experiments); v) once a wave-induced volume of water falls into the overspill basin it should then empty quite rapidly in order to permit the accumulation of the next wave-induced volume and thus maintain the efficiency of the basin; this means that the boundary of the basin should be as permeable as possible; vi) although the use of the overspill basin is proposed here in order to increase the efficiency of existing marina breakwaters in the control of wave overtopping, it should be noted that a similar breakwater section design has also recently been proposed for wave energy harvesting based on turbine activation by the water flowing outside the overspill basin (most recently Vicinanza et al. 2012).

\section{REFERENCES}

Aminti P., Franco L., 2001. Performance of overspill basin on top of breakwaters, Proc. Int. Conf. in Ocean Engineering, Chennai, India, pp.41-46.

Besley, P., 1999. Wave overtopping of seawalls. Design and assessment manual, Hydraulics Research Wallingford. R\&D Technical Report W178. 185705 069X.

Burcharth, H. F. and Lykke Andersen, T. 2006. Overtopping of rubble mound breakwaters with front reservoir, Proceedings of 30th International Conference on Coastal Engineering, ASCE, 46054615.

Crema I., Cappietti L., Aminti P.L. 2009. Laboratory measurements of wave overtopping at plain vertical wall breakwaters in presence of an overspill stilling basin, In: 4th International Short Conference/Course on Applied Coastal Research, pp. 353-360.

ComCoast EU-Interreg IIIb. 2007. North Sea Programme: Hydraulic model tests of an innovative dike crest design, pp. 59.

EurOtop. 2008. - Wave Overtopping of Sea Defences and Related Structures: Assessment Manual, August 2008, pp. 178.

Geeraerts, J., De Rouck, J., Beels, C., Gysens, S. \& DeWolf, P. 2006. Reduction of Wave Overtopping at Seadikes: Stilling Wave Basin, Proceedings of 30th International Conference on Coastal Engineering, ASCE, 4680-4691.

Goda, Y. and Suzuki, Y., 1976. Estimation of Incident and Reflected Waves in Random Wave Experiment, Proceedings of the Fifteenth International Conference on Coastal Engineering, ASCE, Hawaii, pp. 628-650.

Pearson, J., Bruce, T., Allsop, N. W. H., Kortenhaus, A. \& van der Meer, J. W. 2004. Effectiveness of recurve wave walls in reducing wave overtopping on seawalls and breakwaters, Proc. 29th Int. Conf. on Coastal Eng. Lisbon., pp. 4404-4416.

Vicinanza, D., Stagonas, D., Müller, G., Nørgaard, J. H., and Andersen, T. L. 2012. Innovative breakwaters design for wave energy conversion Proceedings of the International Conference on Coastal Engineering, Santander Spain, July 1-6, 2012. 